ARTIGO ORIGINAL

ISSN 1677-5090

(C) 2018 Revista de Ciências Médicas e Biológicas

DOI: http://dx.doi.org/10.9771/cmbio.v17i2.26522

\title{
Expectativas sobre vias de parto entre acadêmicas de psicologia
}

\author{
Expectations regarding the types of delivery among psychology students
}

\author{
Claudia Daiana Borges ${ }^{1 *}$, Rosina Forteski Glidden ${ }^{2}$, Paula Cristiane Bernstein ${ }^{3}$, Raquel Rosa Grigolo ${ }^{3}$, \\ Crisley Fabiane Zastrow ${ }^{3}$, Hugo Guelere Rodrigues ${ }^{3}$
}

\begin{abstract}
${ }^{1}$ Mestra e Doutoranda em Psicologia (UFSC). Docente do Departamento de Psicologia na Uniasselvi-Fameg e docente na Unisociesc; ${ }^{2}$ Mestra e Doutoranda em Educação (UFPR). Docente do Departamento de Psicologia na Uniasselvi-Fameg. ${ }^{3}$ Acadêmico do curso de Psicologia - Uniasselvi-Fameg
\end{abstract}

\begin{abstract}
Resumo
Introdução: vários fatores interferem de maneira significativa na escolha da via de parto. No início da gravidez a maioria das mulheres indica preferência pelo parto normal, entretanto, a maior parte termina por fazer a cesárea. No Brasil, $55 \%$ dos partos realizados são cesáreas e há um predomínio deste tipo de parto, especialmente no sistema privado de saúde. Objetivo: compreender as expectativas de acadêmicas de Psicologia que nunca passaram pela experiência de parto, sobre as vias de parto. Metodologia: foi utilizado como instrumento de coleta de dados um questionário semiestruturado de autoaplicação individual com questões abertas referentes a expectativas em relação ao parto. A pesquisa configura-se como um estudo qualitativo e para análise de dados foi utilizada a análise de conteúdo. Resultados: participaram da pesquisa 109 mulheres, com média de idade de 22,7 anos, desvio padrão de 4,6, que nunca passaram pela experiência de parto. Estas mulheres demonstraram esperar, principalmente, uma assistência médica de qualidade, desejavam o parto normal por este possibilitar uma recuperação melhor e mais rápida, afirmaram sentirem medo que haja complicações e sofrimento no parto e tinham medo da dor. Conclusão: é necessário fornecer à mulher mais informações, apoio e suporte no momento da escolha da via de parto.
\end{abstract}

Palavras-Chave: Parto Normal. Cesárea. Gravidez.

\begin{abstract}
Introduction: various factors significantly interfere in the type of delivery choice. At the start of a pregnancy, the majority of women indicate a preference for a normal delivery, however, a greater part end up having a caesarean delivery. In Brazil, 55\% of deliveries performed are Caesarean, and there is a predominance of this type of delivery especially in the private health care system. Objective: to understand the expectations of Psychology students who have never gone through the experience of delivery regarding the types of delivery. Methodology: a self-administrated semi-structured questionnaire with open questions regarding expectations relating to delivery was utilized as a data collection instrument. The research was configured as a qualitative study, and for the data analysis, content analysis was utilized. Results: the participants were 109 women, averaging 22.7 years old with a standard error of 4.6, who never passed through the childbirth experience. These women hoped, principally, for quality medical assistance, and wished for this to enable a better and faster recovery from normal delivery. They stated that they feared that there would be complications and pain during the delivery, and that they were afraid of the pain. Conclusion: it's necessary to provide more information and support to the woman when choosing the type of delivery.
\end{abstract}

Keywords: Normal Birth. Cesarean Section. Pregnancy.

\section{INTRODUÇÃO}

A escolha da via de parto vem acompanhada de vários fatores, como o medo do desconhecido e da dor, a mudança do papel social da mulher e as informações das pessoas que fazem parte da rede de apoio da gestante. Esses fatores dificultam a identificação da melhor opção de parto de acordo com os desejos da parturiente (SANTOS; MELO; LEAL, 2015; WEIDLE et al., 2014). Para além desses fatores que implicam a escolha da via de parto, surgem processos sociais que reforçam a necessidade de eliminar a imprevisibilidade do parto, fazendo dele

Correspondente/Corresponding: *Claudia Daiana Borges - Uniasselvi-Fameg. Departamento de Psicologia. - End: Rodovia BR 280, 15.885. Guaramirim-SC-Brasil. - Tel: (47) 3373-9800. -Email: claudia.daiana@ gmail.com um novo evento social entre familiares e amigos, e a cesárea permite essa organização. Outra preocupação das mulheres, determinante na escolha da via de parto, é o cuidado com a estética, com a produtividade e a preservação sexual (RISCADO; JANNOTTI; BARBOSA, 2016).

$O$ assunto relacionado à escolha pela via de parto é pouco discutido pelas gestantes e, quando o é, na maioria das vezes, elas buscam pessoas próximas e sem muito domínio do assunto, fazendo emergir na mulher sentimentos de medo e ansiedade. A junção desses fatores influencia no período de gestação e, posteriormente, na escolha da via de parto das gestantes (CAMPOS; ALMEIDA; SANTOS, 2014). A opção pelo parto vaginal, por exemplo, está relacionada à recuperação mais rápida, aversão à cesariana e ao retorno às atividades sexuais em menor tempo. Já a opção pelo parto cesáreo está correlacionada à cesárea 
anterior, realização de laqueadura, medo da dor e receio da sexualidade no pós-parto, orientações do médico e outras doenças que proporcionem risco de morte para a mãe e para o bebê (MINUZZI; REZENDE, 2013; SANTOS; MELO; LEAL, 2015).

No Brasil, $55 \%$ dos partos realizados são cesáreas, há um predomínio deste tipo de parto especialmente no sistema privado de saúde, onde a cesárea representa $84,6 \%$ dos partos realizados, contra $40 \%$ do sistema público (BRASIL, 2016). O excesso de partos cesáreas no Brasil está vinculado à falta de humanização do parto natural, que o torna um processo doloroso, amedrontador e institucionalizado, pela falta de preparo e habilidades para identificação das necessidades da gestante pela equipe de profissionais da saúde. Boa parte das gestantes tem acesso à assistência pré-natal, mas é uma assistência que requer melhoria na qualidade das informações e serviços prestados (SILVA et al., 2015).

O parto normal é um momento de empoderamento da mulher, mas, diante de vários relatos sobre a violência obstétrica as gestantes se sentem coagidas e sem capacidade de parir naturalmente. Por isso, a parturiente acaba assimilando que o parto cesáreo é mais seguro e, assim, estigmatizando o parto normal (WEIDLE et al., 2014). A humanização da atenção ao parto é de extrema importância para que as mulheres se sintam seguras no momento da escolha da via de parto. Aumentar a participação e a percepção das mulheres no processo decisório, tratando-as de maneira a respeitar suas características individuais, oferecendo, além de orientações, suporte emocional, estabelecendo vínculos na relação entre profissionais e gestantes, são determinantes para a mudança do atual paradigma biomédico do nascimento (VELHO; SANTOS; COLLAÇO, 2014).

No início da gravidez a maioria das mulheres demonstra preferência pelo parto normal, pelos benefícios que este traz. Entretanto, os números indicam que, embora a preferência inicial tenha sido o parto normal, muitas fazem a cesárea (MIRANDA, 2012; SANTOS; MELO; LEAL, 2015; WEIDLE et al., 2014). A predileção das parturientes sobre a sua via de parto deve ser considerada e respeitada por seus familiares, amigos e profissionais de saúde, devendo esse último grupo agir como agente de informação para garantir saúde e satisfação para a mãe e o bebê, e não como um agente influenciador para a realização de procedimentos invasivos desnecessários. Deve-se priorizar a natureza e a biologia da gestação, sobre a medicalização e institucionalização, para não transformar o parto em um processo mecânico (SILVA et al., 2015).

Existe um paradoxo entre a escolha inicial da via de parto e o parto propriamente dito. O Brasil registra um número de cesarianas acima do recomendado pela Organização Mundial de Saúde (OMS), que é de 10 a 15\% no total de partos realizados (REIS et al., 2009). Tendo em vista esta contradição que envolve a escolha inicial e a realização efetiva do parto, e todos os fatores envolvidos neste processo, este estudo tem como objetivo compreender as expectativas de acadêmicas de Psicologia sobre as vias de parto.

\section{METODOLOGIA}

Esta pesquisa configura-se como um estudo exploratório e descritivo, de natureza qualitativa. Participaram da pesquisa 109 mulheres acadêmicas de Psicologia cursando do primeiro ao décimo semestre de uma instituição de ensino superior do norte de SC, que atenderam aos seguintes critérios de inclusão: serem acadêmicas do referido curso e instituição, terem idade igual ou superior a 18 anos, nunca terem passado pela experiência de parto e assinarem o Termo de Consentimento Livre e Esclarecido (TCLE). A seleção da amostra foi feita por conveniência, de forma intencional e não probabilística. Os dados foram coletados no mês de março de 2017.

Para a coleta de dados foi utilizado um questionário semiestruturado de autoaplicação individual com questões abertas referentes a expectativas em relação ao parto. Uma dupla de pesquisadores treinados acompanhou a coleta de dados para esclarecer eventuais dúvidas das participantes durante a autoaplicação do questionário. Para a análise de dados foi utilizada a análise de conteúdo, conforme modelo proposto por Ruiz-Olabuenága (2012). Nesta metodologia não há estabelecimento de categorias e subcategorias a priori, estas só emergem a partir da análise do conteúdo. A pesquisa seguiu todas as normas da Resolução 466/12, que regulamenta pesquisa com seres humanos, e sua realização foi aprovada pelo Comitê de Ética do Instituto Superior e Centro Educacional Luterano Bom Jesus em fevereiro de 2017, sob o Parecer número 1.942.472.

\section{RESULTADOS}

\section{Caracterização das participantes}

Participaram deste estudo 109 mulheres acadêmicas de Psicologia que nunca passaram pela experiência do parto. Destas, duas eram grávidas primíparas. Das participantes, $81,7 \%$ tinham até 25 anos; $14,7 \%$, entre 26 e 35 anos e 3,7\%, de 36 a 45 anos, sendo a média de idade de 22,7 anos, com desvio padrão de 4,6. A maioria era solteira $(73,4 \%)$ e branca $(87,9 \%)$. Sobre a formação e vida laboral, $90,7 \%$ não possuíam outra graduação completa e $80,7 \%$ disseram estar empregadas no momento da pesquisa.

\section{Apresentação e discussão dos resultados}

A partir da análise de conteúdo emergiram quatro categorias e suas respectivas subcategorias, sobre as quais serão apresentadas as análises e discussões. A primeira categoria refere-se ao que a participante considerava importante haver no processo de parto, a segunda é sobre o motivo da escolha de uma determinada via de parto, a terceira está relacionada com a expectativa da participan- 
te para seu futuro parto e a última categoria versa sobre os medos em relação ao futuro parto. Para melhor compreensão dos resultados, cada categoria será apresentada inicialmente em um quadro com a descrição da categoria, subcategorias e frequência de cada subcategoria.

\section{Fatores importantes no parto}

Quadro 1 - O que considera importante haver no processo do parto

\begin{tabular}{|l|l|c|}
\hline Categoria & Subcategoria & Frequência \\
\hline \multirow{4}{*}{$\begin{array}{l}\text { 1. O que considera } \\
\text { importante haver no } \\
\text { processo do parto }\end{array}$} & $\begin{array}{l}\text { Assistência médica de } \\
\text { qualidade }\end{array}$ & 23 \\
\cline { 2 - 3 } & $\begin{array}{l}\text { Informação e conhecimento } \\
\text { Cegurança e saúde para }\end{array}$ & 20 \\
\cline { 2 - 3 } & $\begin{array}{l}\text { Assistência de profissionais } \\
\text { mape bebê }\end{array}$ & 17 \\
\cline { 2 - 3 } & Cuidado & 16 \\
\cline { 2 - 3 } & $\begin{array}{l}\text { Ambiente e materiais } \\
\text { adequados }\end{array}$ & 12 \\
\cline { 2 - 3 } & Apoio & 10 \\
\cline { 2 - 3 } & Humanização & 10 \\
\cline { 2 - 3 } & Paciência & 10 \\
\hline
\end{tabular}

Fonte: Dados da própria pesquisa.

A primeira categoria elucida aspectos que as participantes consideravam importante haver no processo do parto. Essa categoria foi subdividida em nove subcategorias. A primeira delas, "assistência médica de qualidade", foi a mais frequente, tendo sido citada por 23 participantes que enfatizaram o papel do médico no processo do parto, conforme pode ser verificado na resposta de duas participantes que reafirmaram a importância do acompanhamento deste profissional:

\section{"Um bom acompanhamento médico." (P52) \\ "Médicos experientes para um parto bem sucedido." (P18)}

A assistência médica como fator importante no processo de parto também foi identificada em outros estudos (ARIK, 2017; LEGUIZAMON JUNIOR; STEFFANI; BONAMIGO, 2013; ZANARDO; CELDERÓN; HABIGZANG, 2017). Os participantes da pesquisa de Ferreira Junior et al. (2017) citaram a importância do acompanhamento, orientação e assistência médica, os profissionais desta área devem informar a parturiente sobre as vantagens, desvantagens e peculiaridades de cada tipo de parto. Esta informação confirma a atual ênfase na figura do médico como único profissional com capacidade para assistência ao parto (MIRANDA et al., 2008).

A segunda subcategoria foi citada por 20 participantes e se refere a "informação e conhecimento". Nesta subcategoria elucidou-se a necessidade que as mulheres sentem de estarem bem informadas sobre o assunto, fato também verificado em outro estudo que demonstrou a insatisfação das participantes quanto às informações e orientações fornecidas pelos profissionais de saúde sobre a gestação e o parto (WEIDLE et al., 2014). Conhecimento e informação são essenciais para o protagonismo da mulher no processo do parto, pois com informações fidedignas ela terá maior segurança, participação, autonomia e empoderamento na escolha de como nascerá seu filho. A falta de conhecimento influencia o comportamento das parturientes, deixando-as inseguras e vulneráveis a aceitar a decisão de terceiros (PATAH; MALIK, 2011; VELHO; SANTOS; COLLAÇO, 2014; WEIDLE et al., 2014).

A terceira subcategoria mais citada foi a "assistência de profissionais capacitados", com 17 menções. Essa subcategoria traz à tona a importância de haver outros profissionais bem capacitados, além do médico, no processo do parto, convergindo com as atuais políticas públicas que preveem uma atuação interdisciplinar. Por exemplo, os profissionais da Enfermagem, que são conhecedores da obstetrícia e passaram a atuar, no setor público, com práticas direcionadas à melhoria da qualidade da assistência para as mães e bebês, o que demonstra uma ampliação da equipe diretamente envolvida com o parto (CASTRO; CLAPIS, 2005; OSAVA, 1997). A participante 53 demonstrou que espera ser atendida por um profissional capacitado, seja ele médico ou não:

"Alguém que faça o parto, seja uma parteira ou médico." (P53)

Enfermeiras, parteiras e doulas têm um papel importante não só na redução dos partos cesarianos, mas também na naturalização do parto e na humanização da assistência (FRIGO et al., 2013; MALHEIROS et al., 2012; OSAVA, 1997; SANTOS; OKAZAKI, 2012). A presença de outros profissionais capacitados no processo do parto também foi identificada no estudo de Santos e Nunes (2009) que investigou a assistência ao parto por doulas. Os participantes do referido estudo consideravam que as doulas atuam no apoio emocional, substituem a presença de um familiar e prestam apoio à equipe (SANTOS; NUNES, 2009). Já os resultados do estudo de Pereira, Franco e Baldin (2011) não demonstraram a importância de outros profissionais, além do médico, no processo de parto, evidenciando um modelo de hospitalização brasileiro que centraliza na figura do médico a escolha e o comando do parto.

"Segurança e saúde para mãe e o bebê" é a quarta subcategoria, com 16 citações. Esse fator também foi identificado no estudo de Pimenta et al. (2013), no qual as participantes relataram sentir segurança no parto, não relatando incapacidade, de modo que sentir-se segura permitiu vivenciar a experiência do parto escolhido. Oliveira et al. (2010) destacam que a parturiente almeja um ambiente que a deixe confortável, onde receba cuidado, afeto e atenção, favorecendo a sua segurança e seu bem-estar. A segurança também está relacionada com o conhecimento da parturiente sobre os riscos e benefícios 
de cada via de parto, pois, em poder de informações fidedignas, ela terá maior participação, autonomia e empoderamento na escolha de como nascerá seu filho (PATAH; MALIK, 2011; VELHO; SANTOS; COLLAÇO, 2014; WEIDLE et al., 2014).

A subcategoria "cuidado" apresentou 15 citações e demonstra a expectativa das participantes de se sentirem cuidadas no processo do parto. Essa necessidade foi verificada no estudo de Carraro et al. (2006) que identificou que, diante da exposição da parturiente aos riscos que o parto apresenta, é preciso haver um acolhimento individualizado para que ela se sinta respeitada, confortada e cuidada. Duarte e Andrade (2006) contribuem, afirmando que o profissional da Enfermagem tem um importante papel neste sentido, por ter um contato direto com a parturiente ele pode oferecer o apoio e cuidado que ela precisa.

A subcategoria "ambiente e materiais adequados" foi mencionada por 12 participantes e expressa a importância do ambiente para o bom andamento do processo. Por outro lado, o estudo de Macedo et al. (2005) identificou que um ambiente inadequado pode prejudicar o trabalho de parto. Os resultados do referido estudo demonstraram que o ambiente inadequado de pré-parto pode reduzir as atitudes de enfrentamento da parturiente em relação à dor, impedindo que esta assuma as suas reações instintivas que contribuem para a evolução fisiológica do trabalho de parto. Neste sentido, fica evidente a necessidade da humanização em todos os aspectos que envolvem o parto, inclusive o ambiente físico.

As subcategorias "apoio", "humanização" e "paciência" foram citadas por 10 participantes e demonstram a necessidade que elas sentiam de receber este tipo de atenção qualificada. Tal demanda pode ser verificada na resposta de duas participantes que relataram a importância de um atendimento humanizado e com apoio:

"Apoio médico, psicológico, que forneça segurança e acalento para ambas as partes." (P09)

"Humanização, respeito com a mulher." (P22)

Essas subcategorias evidenciam a importância de fatores que vão além de boa assistência médica e profissional, e que requerem uma atenção integral e humanizada. A pesquisa de Dornfeld (2011) apontou resultados neste sentido. Nela o processo empático da equipe de saúde através da escuta, presença e afirmação foram fatores que possibilitaram uma experiência positiva com o parto, influenciando no vínculo da mãe com o bebê. Também no estudo de Carraro et al. (2006) as participantes ressaltaram a relevância do cuidado humanizado com a mãe e o bebê para a criação do vínculo entre eles. Em consonância, no estudo de Santos et al. (2011) as participantes relataram a necessidade de que no atendimento da parturiente sejam consideradas as singularidades e especificidades de cada fase, superando modelos padronizados e não humanizados de atendimento. Para Martins et al. (2005), o apoio e o respeito da equipe de saúde com as parturientes e seus familiares são condições essenciais para a humanização do parto.

\section{Motivações envolvidas na escolha da via de parto}

Quadro 2-Motivo da escolha de uma determinada via de parto

\begin{tabular}{|c|c|c|}
\hline Categoria & Subcategoria & Frequência \\
\hline \multirow{7}{*}{$\begin{array}{l}\text { 2. Motivo da } \\
\text { escolha de uma } \\
\text { determinada via } \\
\text { de parto }\end{array}$} & $\begin{array}{l}\text { Parto normal, pela recuperação ser } \\
\text { melhor e mais rápida }\end{array}$ & 38 \\
\hline & Cesárea para evitar dor e sofrimento & 23 \\
\hline & $\begin{array}{l}\text { Parto normal, porque é mais } \\
\text { benéfico para mãe e bebê }\end{array}$ & 20 \\
\hline & $\begin{array}{l}\text { Parto normal, porque é uma via de } \\
\text { parto humanizada e natural }\end{array}$ & 16 \\
\hline & $\begin{array}{l}\text { Cesárea, porque é mais segura e } \\
\text { confortável }\end{array}$ & 15 \\
\hline & $\begin{array}{l}\text { A opção pela cesárea seria só em } \\
\text { casos de risco }\end{array}$ & 8 \\
\hline & $\begin{array}{l}\text { Cesárea, pelas informações de } \\
\text { experiências negativas que outras } \\
\text { mulheres tiveram com o parto } \\
\text { normal }\end{array}$ & 7 \\
\hline
\end{tabular}

Fonte: Dados da própria pesquisa.

A segunda categoria apresenta o motivo da escolha de uma determinada via de parto. Esta categoria foi subdividida em sete subcategorias, e "parto normal pela recuperação ser melhor e mais rápida" foi a mais frequente, tendo sido citada por 38 participantes.

\section{"Pela recuperação mais rápida que o normal proporciona." (P10)}

Entre as participantes deste estudo, a preferência pelo parto normal está associada ao fato de este possibilitar uma rápida recuperação, dado que converge com o que foi verificado na pesquisa de Souza, Furtado e Nishida (2016), em que a recuperação mais rápida motivou a escolha de gestantes pelo parto normal. Outros estudos (MIRANDA, 2012; SANTOS; MELO; LEAL, 2015; WEIDLE et al., 2014) indicam também que, pelo menos inicialmente, existe um maior desejo pelo parto normal por parte das futuras mães, tendo por base o modelo natural/fisiológico que é considerado mais saudável para gestante e bebê, e por este proporcionar uma recuperação mais rápida (MIRANDA, 2012; SANTOS; MELO; LEAL, 2015; WEIDLE et al., 2014).

A segunda subcategoria, citada por 23 mulheres, foi a "cesárea para evitar dor e sofrimento".

"Para não sentir dor." (P14)

"Porque oferece menos sofrimento." (P109)

As pesquisas (BRASIL, 2014; FERREIRA JUNIOR et al., 2017; MEDEIROS et al., 2017) indicam que um dos benefícios da cesariana é a menor dor no trabalho de parto, por este ser sempre realizado com anestesia. Sendo este o principal motivo alegado pelas brasileiras que escolhem 
a cesariana como uma via de parto (CÂMARA et al., 2016). O medo da dor pós-cirurgia ou no momento do parto pode influenciar na escolha da via de parto, conforme apontam os estudos de Reis et al. (2009) e Pereira, Franco e Baldin (2011).

O "parto normal, porque é mais benéfico para mãe e bebê" é a terceira subcategoria mais citada, com 20 participantes, e vai ao encontro dos resultados da pesquisa de Souza, Furtado e Nishida (2016), em que as participantes mencionaram o melhor desenvolvimento do bebê e a rápida recuperação da mãe como pontos positivos para o parto normal. A maioria das participantes da pesquisa de Medeiros et al. (2017) também relatou o desejo pelo parto normal no início da gestação devido aos benefícios para mãe e bebê que este tipo de parto proporciona.

A via de parto normal traz algumas vantagens para a mãe e para o bebê. Dentre elas estão o menor índice de prematuridade, o favorecimento da respiração do bebê, menor dor após o parto, infecção puerperal mais rara, o aleitamento materno mais fácil, recuperação mais rápida, custo e cicatriz menores, risco de morte muito baixo, futuras gestações com menor risco e complicações menos frequentes. Por outro lado, como desvantagem, pode-se destacar as dores no trabalho de parto (BRASIL, 2014).

A quarta subcategoria expõe a escolha pelo "parto normal, porque é uma via de parto humanizada e natural", e foi mencionada por 16 participantes. $O$ relato abaixo exemplifica a preferência pelo curso natural:

"É mais natural, quando e bebê estiver pronto ele vai nascer, sem nenhum processo forçado." (P18)

Ter um parto humanizado e que respeite o curso natural do processo era algo esperado por 16 participantes do presente estudo e demonstra o desejo de serem acolhidas e apoiadas no momento do parto. Este dado vai ao encontro dos resultados de outras pesquisas que também verificaram a preferência das mulheres pelo parto normal por este respeitar a condição natural do processo (MIRANDA, 2012; SANTOS; MELO; LEAL, 2015; WEIDLE et al., 2014). As gestantes que participaram da pesquisa de Guedes et al. (2016) também consideraram o parto normal como algo positivo, saudável e natural, uma experiência que gostariam de vivenciar. Mabuchi e Fustione (2008) destacam que ter um parto seguro, acolhedor, que respeite as necessidades físicas e emocionais é direito de todas as parturientes.

A subcategoria "cesárea, porque é mais segura e confortável" foi a quinta mais frequente, estando presente no relato de 15 participantes que expuseram um entendimento de que o parto normal as expõe a situações de risco e desconforto:

"Acho que o parto normal exige muito da mulher, ficar horas, talvez um dia em trabalho de parto não deveria ser considerado normal." (P85)

"E menor exposição a situações constrangedoras e desrespeito como por exemplo a violência obstétrica." (P109)

O medo de sofrer violência obstétrica no parto normal apareceu neste estudo como um dos fatores que motivaram a escolha pela cesárea. Na pesquisa de Weidle et al. (2014) foi verificado que o relato de outras mulheres que já haviam sofrido violência obstétrica desencorajou as gestantes a parir naturalmente. Assim, para os autores, a parturiente acaba assimilando que o parto cesáreo é mais seguro e estigmatizando o parto normal. Entender a cesárea como mais segura e confortável foi uma realidade entre as participantes desta pesquisa e converge com os resultados do estudo de Medeiros et al. (2017), no qual as participantes relataram a preferência pela cesárea para evitar desfechos inesperados e trágicos no processo do parto.

A subcategoria "a opção pela cesárea seria só em casos de risco", a sexta mais citada, foi mencionada oito vezes e indica a preferência por este tipo de parto somente em situação de perigo para mãe ou para o bebê, conforme pode ser verificado no relato de duas participantes:

"Cesárea é um recurso para possíveis riscos." (P17)

"Fazer cesárea só se houver alguma complicação." (P74)

Na pesquisa de Ribeiro et al. (2016), também foi verificado que as participantes reconheceram a importância do parto cesáreo diante de complicações, mesmo não o considerando como a melhor opção. Esse dado é corroborado pelos estudos de Medeiros et al. (2017), em que as parturientes optaram pelo parto cesáreo devido a intercorrências que colocaram a mãe e o bebê em situação de risco. Em alguns casos, a indicação para realização de cesariana é necessária, como em situações em que o feto não é reativo, tem apresentação pélvica, a gestante tem HIV, a posição é transversa, entre outras situações específicas em que o obstetra avalia a necessidade da realização da cesárea (BRASIL, 2014).

A última subcategoria, citada por sete participantes, foi a "cesárea, pelas informações de experiências negativas que outras mulheres tiveram com o parto normal" e demonstra a influência da experiência de outras mulheres para a escolha da cesárea:

"Por escutar muitas histórias ruins sobre parto normal." (P14)

"Mediante alguns relatos optaria pela cesárea. Relatos de dor, evacuação, sentar-se em uma bola para fazer o bebê nascer, horas de trabalho de parto." (P16)

As histórias sobre a dor, sofrimento e abusos influenciaram a opinião das mulheres participantes deste estudo, o que corrobora com o resultado de outra pesquisa onde as participantes afirmaram ter escolhido a via de parto pelas experiências, interpretações e significados de vivências de outras mulheres de sua rede de contato (LAGOMAR- 
SINO et al., 2013). Fica claro que a troca de informações entre familiares e amigas sobre as experiências com o parto, bem-sucedidas ou não, pode induzir a mulher a fazer a sua escolha sem considerar as particularidades do seu caso (SILVA; PRATES; CAMPELO, 2014).

\section{Expectativas para o futuro parto}

Quadro 3-O que espera do seu futuro parto

\begin{tabular}{|l|l|c|}
\hline Categoria & \multicolumn{1}{|c|}{ Subcategoria } & Frequência \\
\hline \multirow{5}{*}{$\begin{array}{l}\text { 3. O que espera do } \\
\text { seu futuro parto }\end{array}$} & $\begin{array}{l}\text { Tem medo de que haja } \\
\text { complicações no parto }\end{array}$ & 40 \\
\cline { 2 - 3 } & $\begin{array}{l}\text { Espera que corra tudo bem e } \\
\text { não haja complicações }\end{array}$ & 27 \\
\cline { 2 - 3 } & $\begin{array}{l}\text { Espera que o parto seja } \\
\text { tranquilo }\end{array}$ & 24 \\
\cline { 2 - 3 } & $\begin{array}{l}\text { Não sente medo em relação } \\
\text { ao futuro parto }\end{array}$ & 15 \\
\cline { 2 - 3 } & Não tem expectativas & 14 \\
\cline { 2 - 3 } & $\begin{array}{l}\text { Espera que o parto seja } \\
\text { rápido }\end{array}$ & 9 \\
\cline { 2 - 3 } & $\begin{array}{l}\text { Espera ter assistência médica } \\
\text { qualificada }\end{array}$ & 8 \\
\hline
\end{tabular}

Fonte: Dados da própria pesquisa.

A terceira categoria apresenta o eixo "O que espera do seu futuro parto", tendo como a primeira subcategoria "tem medo que haja complicações no parto", que inclui o relato de 40 mulheres:

"Medo por ser uma situação médica que envolve riscos - emergência, hemorragia, dificuldade de recuperação, risco de infecção." (P19)

O medo de complicações no parto também foi um dado verificado no estudo de Tostes e Seidel (2016), no qual as participantes expressaram a preocupação com o sofrimento da mãe e do bebê. Outra preocupação foi identificada entre as participantes dos estudos de Medeiros et al. (2017) e Oliveira et al. (2010), que afirmaram ter medo de que complicações no parto as impossibilitassem de vivenciar os primeiros momentos com o filho.

A segunda subcategoria, "espera que ocorra tudo bem e não haja complicações", mencionada por 27 participantes, expõe uma visão positiva quanto ao parto:

"Espero que não tenha complicações, que meu bebê seja saudável e minha recuperação seja rápida." (P42)

As expectativas positivas relatadas pelas participantes deste estudo convergem com os dados da pesquisa de Pereira e Leal (2015), em que as participantes apresentaram boas expectativas em relação ao que iria acontecer durante o parto, sobressaindo o sentimento positivo em comparação às preocupações e medos. Aspectos positivos relacionados ao parto e ao nascimento são promovidos com assistência humanizada focada na mulher e na família. Tal assistência possibilita que indicadores de morbidade e mortalidade sejam mais baixos e que aspectos benéficos emocionais, sociais e culturais sejam características desse processo de humanização da assistência à parturiente (BRASIL, 2014).

A terceira subcategoria, "espera que o parto seja tranquilo", foi mencionada por 24 mulheres e relaciona-se com a quarta subcategoria, "não sente medo em relação ao futuro parto", citada por 15 participantes. Tais subcategorias demonstram que estas mulheres não sentiam medo e esperavam um parto tranquilo:

"Que ocorra de forma tranquila, sem nenhum contratempo, de maneira organizada propondo bem estar e saúde aos envolvidos no processo." (P09)

"Não tenho medo. Muitas mulheres passam e já passaram por isto e continuam a ter bebês." (P08)

Os achados destas categorias corroboram com os resultados da pesquisa de Tostes e Seidel (2016), em que oito participantes afirmaram que entendiam o parto como uma situação agradável, percebendo a parturição unicamente como um processo pelo qual chegará o bebê. Santos, Melo e Leal (2015) e Weidle et al. (2014) sinalizam a importância da informação para que a expectativa em relação ao parto não seja de medo, uma vez que a escoIha da via de parto vem acompanhada de vários fatores, como o medo do desconhecido e da dor e as mudanças do papel social da mulher. Por isto, informação e apoio são fundamentais.

A subcategoria "não tem expectativas" esteve presente neste estudo, sendo a quinta subcategoria mais frequente, com 14 menções. Os relatos elucidam que, para estas participantes, tudo irá depender do momento e contexto, por isto elas não mantêm expectativas atualmente:

"Por enquanto nenhuma. No momento ter filhos está fora de questão." (P07)

"Não tenho expectativas tudo vai depender muito do momento em que vou estar vivenciando o parto". (P81)

Os resultados das pesquisas de Rezende (2015) e Pereira e Leal (2015) também indicam que o distanciamento temporal com o parto interfere nas expectativas futuras, havendo uma diferença em relação às expectativas daquelas em que a gravidez é uma realidade próxima, e as daquelas que ainda não têm planos. Para estas, a tendência é adotar uma postura defensiva, demonstrando sentir confiança e não querer imaginar o momento do parto. Esta postura é compreendida como uma estratégia para lidar com a complexidade do tema.

A sexta subcategoria, "espera que o parto seja rápido", com nove relatos, é corroborada pela categoria encontrada no estudo de Pereira e Leal (2015), que foi citada por 21 gestantes que afirmaram ter a expectativa de que o parto seja fácil e ocorra rapidamente. Esta expectativa está relacionada com um desejo da mulher de possuir um maior controle no processo do parto, esperando vivenciar algo único e sem muitas interferências médicas. 
Este aspecto é mencionado com uma percepção positiva em relação ao parto.

A sétima e última subcategoria foi à "espera ter assistência médica qualificada", citada por oito participantes, e atesta que, para estas participantes, era essencial a capacitação dos profissionais envolvidos no processo do parto:

"Que o profissional seja realmente capacitado, fazendo um trabalho bem feito sem gerar futuros problemas." (P93)

A preocupação com a capacitação profissional e qualidade na assistência também foi verificada no estudo de Hamerski e Van der San (2003), em que mulheres no primeiro parto expressaram a necessidade de uma assistência qualificada no pré-natal, no nascimento e no pós-parto, além da necessidade de auxílio para a diminuição do medo da dor. Em relação a este fato, Silva et al. (2015) identificaram a importância de a equipe de saúde ser qualificada para desenvolver melhor suas funções e oferecer um atendimento individualizado e humanizado à parturiente, destacando a importância da capacitação específica para os profissionais que atuam no processo do parto.

\section{Medos presentes nas expectativas}

Quadro 4 - Medos em relação ao futuro parto

\begin{tabular}{|c|c|c|}
\hline Categoria & Subcategoria & Frequência \\
\hline \multirow{4}{*}{$\begin{array}{l}\text { 4. Medos em relação } \\
\text { ao futuro parto }\end{array}$} & Medo da dor & 25 \\
\hline & $\begin{array}{l}\text { Medo de sofrer Violência } \\
\text { Obstétrica }\end{array}$ & 12 \\
\hline & $\begin{array}{l}\text { Medo do processo como } \\
\text { um todo }\end{array}$ & 7 \\
\hline & Medo da Morte & 5 \\
\hline
\end{tabular}

Fonte: Dados da própria pesquisa.

A última categoria versa sobre os medos em relação ao futuro parto. 0 "Medo da dor" representa a subcategoria mais frequente, tendo sido mencionada por 25 participantes que identificaram a dor como um fator relevante em suas expectativas, conforme pode ser verificado nos relatos a seguir:

"Tenho muito medo da dor que todos polemizam. Mas acredito que a calma ajuda muito nesta hora." (P49)

"Tenho medo de sentir muita dor." (P107)

O medo da dor em relação ao parto também foi discutido em outros estudos que apontam que fatores como medo da dor pós cirurgia ou de não "aguentar", de não "dar conta" do parto, podem influenciar na escolha da via de parto (PEREIRA; FRANCO; BALDIN, 2011; REIS et al., 2009). Estes mesmos estudos identificaram ainda outros fatores de influência como o acesso a um atendimento médico diferenciado, o respeito à escolha da via de parto, agendamento prévio do médico e da gestante e temor de procedimentos, como o uso de fórceps. Segundo os autores, as influências ocorrem através das mídias e da representação social sobre o parto. A dor e o sofrimento também estão estruturados no modelo biomédico e desumanizado da assistência hospitalar (PEREIRA, FRANCO, BALDIN; 2011; REIS et al., 2009).

A segunda subcategoria mais frequente foi o "medo de sofrer violência obstétrica", citada por 12 mulheres que expuseram seus medos em relação a sofrer algum tipo de violência no momento do parto:

"Medo de ser machucada e maltratada." (P20)

O parto é um momento único na vida da gestante, devendo a atenção dos profissionais ser a mais humana e natural possível. Os cuidados hospitalares necessitam oferecer apoio à parturiente, acolhimento, atenção e humanização. Observa-se que a violência obstétrica ocorre desde a não explicação para a realização de procedimentos médicos, até o uso de palavras ofensivas durante a parturição. Esse tipo de violência é pouco reconhecido pelas mulheres, pois elas vivenciam naquele momento emoções que as fazem calar. Sendo assim, é necessário, desde as consultas pré-natais, abordar assuntos que possuam relação com a violência obstétrica, a fim de orientar a mulher para a tomada de decisão no que se referir ao seu corpo e sua parturição (ANDRADE; AGGIO, 2014).

A terceira subcategoria foi relatada por sete participantes e indica o "medo do processo como um todo", trazendo à tona a insegurança da mulher para viver essa experiência:

"Sonho muito em ser mãe, mas fico pensando na hora do parto e tenho receio." (P51)

"Na verdade tenho muito medo." (P69)

Esses dados correspondem aos encontrados no estudo de Leite et al. (2014), no qual se observou uma certa ambivalência de sentimentos das parturientes em relação ao processo gestacional. Além da felicidade pela gestação, estava presente o medo do desconhecido, do que estava por vir, era uma sensação que assombrava as futuras mães. Esses sentimentos, até então nunca experienciados, demonstram a importância de a gestante receber informações, tanto no que se refere aos fatores biológicos, quanto aos emocionais relacionados ao parto e à maternidade. Neste contexto, os profissionais de saúde possuem um papel fundamental ao oferecer orientações sobre o processo da gestação e instruções que visem melhorar a saúde da gestante e inteirá-la dos acontecimentos que envolvem todo o processo de parturição (LEITE et al., 2014).

O "medo da morte" é a quarta subcategoria, tendo sido citada por cinco participantes. O relato a seguir exemplifica como este sentimento se expressa:

"Sim, medo de ter que decidir entre a minha vida e a do 
meu filho se algo ocorrer ... Receio de perder a vida ou o bebê, ter que escolher entre mim ou ele." (P53)

O medo diante da ideia da própria morte ou da morte do bebê também foi citado na pesquisa de Rodrigues e Siqueira (2008), na qual as mães afirmaram temer pela vida delas e de seus filhos. No presente estudo, o sentimento de medo mostrou-se recorrente no relato de muitas participantes, indicando a insegurança que as mulheres sentem em relação ao futuro parto. Nesse sentido, a pesquisa de Bezerra e Cardoso (2006) também destacou o medo do processo de parto como uma realidade. As autoras associam este fato à mecanização da prática obstétrica, dotada de procedimentos desde a gestação, deixando a mulher insegura e ansiosa.

\section{CONCLUSÃO}

Este estudo teve como objetivo compreender as expectativas de acadêmicas de Psicologia sobre as vias de parto e os resultados versaram sobre o que as participantes consideravam importante haver no processo do parto, as motivações para a escolha de uma determinada via de parto, o que elas esperavam e quais os medos relacionados ao seu futuro parto. Entre os fatores que as acadêmicas consideravam importante haver no processo do parto, estão a assistência profissional, ambiente e materiais de qualidade, bem como informações e um atendimento humanizado. Tais fatores contribuíam para que as participantes se sentissem mais seguras sobre a via de parto que será realizada.

Quanto ao motivo da escolha de determinada via de parto, a maioria das participantes que optariam pelo parto normal citaram como motivação o fato de o parto normal possibilitar uma recuperação melhor e mais rápida. Já as participantes que optariam pela cesárea o fariam para evitar dor e sofrimento. Em relação às expectativas, a maioria relatou sentir medo de que haja complicações no parto, demonstrando ainda uma crença que associa o parto às intercorrências, o que também se relaciona com os principais medos citados pelas participantes, que foram o medo da dor e de sofrer violência obstétrica.

A presente pesquisa confirma dados já encontrados em outros estudos, especialmente no que se refere ao medo que as mulheres sentem de não serem respeitadas, desde a sua escolha, até no momento do parto. Por outro lado, houve várias menções relacionadas à humanização no parto, confirmando a importância de o atendimento à gestante priorizar o respeito, afeto e atenção, garantindo o seu direito de autonomia para tomada de decisões. Tais fatores reforçam a necessidade do fortalecimento de políticas públicas direcionadas para o processo do parto que garantam para a gestante informação, apoio, acolhimento e um atendimento humanizado, seja no parto normal ou na cesárea.

Embora o estudo tenha alcançado seu objetivo, o fato de ter sido realizado exclusivamente com estudantes de psicologia pode ser uma limitação, já que isso remete a uma possibilidade de maiores conhecimentos e informações sobre os benefícios e riscos de cada tipo de parto. Sugere-se a realização de outros estudos que tenham como participantes acadêmicas de outros cursos, para relacionar o acesso à formação profissional, com maiores esclarecimentos sobre o tema.

\section{REFERÊNCIAS}

ANDRADE, B. P.; AGGIO, C. de M. Violência obstétrica: a dor que cala. IN: SIMPÓSIO GÊNERO E POLÍTICAS PÚBLICAS, 3., 2014. Anais... Universidade Estadual de Londrina, 27 a 29 de maio de 2014.

ARIK, R. M. Decisão pelo tipo de parto: estratégia educativa para a promoção do parto vaginal. 2017. Dissertação (Mestrado em Enfermagem) - Faculdade de Medicina, Universidade Estadual Paulista "Júlio de Mesquita Filho", Botucatu, 2017

BEZERRA, M. G. A.; CARDOSO, M. V. M. L. Fatores culturais que interferem nas experiências das mulheres durante o trabalho de parto. Rev. Latino-Am Enfermagem, São Paulo, v. 14, n.3, p. 414-121, 2006.

BRASIL. Ministério da Saúde. Humanização do parto e do nascimento. Brasília: MS, 2014. (Cadernos Humaniza SUS, v. 4).

BRASIL. Ministério da Saúde. Portaria n³06, de 28 de março de 2016. Aprova as diretrizes de atenção à gestante: a operação cesariana. Diário Oficial [da] União, Brasília, 2016.

CÂMARA, R. et al. Cesariana a pedido materno. Rev. Col. Bras. Cir., Rio de Janeiro, v. 43, n.4, p. 301-310, 2016.

CAMPOS, A. S.; ALMEIDA, A. C. C. H.; SANTOS, R. P. Crenças, mitos e tabus de gestantes acerca do parto normal. Rev. Enferm. UFSM, Santa Maria, v. 2, n. 4, p.332-341, 2014.

CARRARO, T. E. et al. Cuidado e conforto durante o trabalho de parto e parto: na busca pela opinião das mulheres. Texto \& contexto enferm., Florianópolis, v.15, p. 97-104, 2006

CASTRO, J. C. de; CLAPIS, M. J. Parto Humanizado na percepção das enfermeiras obstétricas envolvidas com assistência ao parto. Rev Latino-Am Enfermagem, v.13, n. 6, p. 960-967, 2005.

DORNFELD, D. A equipe de saúde e a segurança do binômio mãe-bebê no parto e nascimento. 2011. Dissertação (Mestrado em Enfermagem) - Escola de enfermagem, Universidade Federal do Rio Grande do Sul, Porto Alegre, 2011

DUARTE, S. J. H.; ANDRADE, S. M. O. de. Assistência pré-natal no Programa Saúde da Família. Esc. Anna Nery Rev. Enferm., Rio de Janeiro, v.10, n.1, p.121-125, 2006

FERREIRA JUNIOR, A. R. et al. Discurso de mulheres na experiência do parto cesáreo e normal. Revista Saúde.com, Jequié, v.13, n. 2, p. 855-862, 2017

FRIGO, J. et al. A enfermagem e o cuidado humanístico na parturição. Revista UNINGÁ, Maringá, v.15, n.2, p. 5-9, 2013.

GUEDES, W. G. et al. Conhecimento de gestantes quanto aos benefícios do parto normal na consulta pré-natal. Rev. enferm. UFPE, Recife, v.10, n.10, p. 3860-3867, 2016.

HAMERSKI, L. M.; VANDERSAND, I. C. P. Mulheres no primeiro parto: suas expectativas. Revista contexto \& saúde, Rio Grande do Sul, n.5, p. $67-92,2003$.

LEGUIZAMON JUNIOR, T.; STEFFANI, J. A.; BONAMIGO, E. L. Escolha da via de parto: expectativa de gestantes e obstetras. Rev. bioméd, Yucatan, v. 21 , n. 3 , p. 509-517, 2013 
LAGOMARSINO, B. S. et al. A cultura medindo preferências pelo tipo de parto: entrelaçamento de fios pessoais, familiares e sociais. REME rev. min. enferm., Belo Horizonte, v.17, n.3, p. 680-687, 2013.

LEITE, M. G. et al. Sentimentos advindos da maternidade: revelações de um grupo de gestantes. Psicol. Estud., Maringá, v.19, n.1, p.115124, 2014.

MABUCHI, A. dos S.; FUSTIONI, S.M. O significado dado pelo profissional de saúde para trabalho de parto e parto humanizado. Acta paul. enferm., São Paulo, v. 21, n.3, p. 420-421, 2008.

MACEDO, P. de O. et al. Percepção da dor pela mulher no pré-parto: a influência do ambiente. Rev. enferm. UERJ, Rio de Janeiro, v.13, n. 3, p. 306-312, 2005.

MALHEIROS, P. A. et al. Parto e nascimento: saberes e práticas humanizadas. Texto \& contexto enferm., Florianópolis, v. 21, n.2, p. 329-337, 2012.

MARTINS, C. A. et al. Casas de parto: sua importância na humanização da assistência ao parto e nascimento. Rev. Eletrônica Enferm., Goiânia, v.7, n.3, p. 360-365, 2005.

MEDEIROS, R. M. K. et al. Aspectos relacionados à preferência da gestante pela via de parto. Revista Eletrônica Gestão \& Saúde, Brasília, v.8, n.1, p. 603-621, 2017.

MINUZZI, A.; REZENDE, C. L. Fatores de influência na escolha da via de parto: uma revisão de literatura. UNINGÁ, Maringá, v. 14, n.1, p. $37-48,2013$.

MIRANDA, D. B. et al. Parto normal e cesárea: representações de muIheres que vivenciaram as duas experiências. Rev. Eletrônica Enferm., Goiânia, v. 10, n. 3, p. 337-346, 2008.

MIRANDA, T. A. "Ciência”, “Natureza” e a normatização institucional do parto. 2012. 127 f. Dissertação (Mestrado Profissionalizante em Saúde e Gestão do Trabalho) - Universidade do Estado do Rio de Janeiro, Instituto de Medicina Social, Rio de Janeiro. 2012.

OLIVEIRA, A. S. S. de. et al. Percepção de mulheres sobre a vivência do trabalho de parto e parto. Revista Rene, [s.I], v.11, p.32-41, 2010.

OSAVA, R. H. Assistência ao parto no Brasil: o lugar do não-médico. 1997. 27f. Tese (Doutorado em Saúde Materno-Infantil) - Programa de Pós-Graduação da Faculdade de Saúde Pública da Universidade de São Paulo, São Paulo, 1997.

PATAH, L. E. M.; MALIK, A. M. Modelos de assistência ao parto e taxa de cesárea em diferentes países. Rev. Saúde Pública, São Paulo, v. 45, n.1, p.185-194, 2011.

PEREIRA, M.; LEAL, I. Terceiro trimestre de gravidez: expectativas e emoções sobre o parto. Psicol. saúde doenças, Lisboa, v.16, n.2, p. 254-266, 2015.

PEREIRA, R. da R.; FRANCO, S. C.; BALDIN, N. A dor e o protagonismo da mulher na parturição. Rev. bras. anestesiol., Rio de Janeiro, v. 61, n.3, p. 376-388, 2011.

PIMENTA, L. F. et al. A cultura interferindo no desejo sobre o tipo de parto. Rev. pesqui. cuid. fundam., Rio de Janeiro, v. 6, n.3, p. 987-997, 2013.

REZENDE, C. B. O parto em contexto: narrativas da gravidez entre gestan- tes no Rio de Janeiro. Civitas, Porto Alegre, v. 15, n. 2, p. 214-228, 2015.

RIBEIRO, J. F. et al. Experiência de parto: percepção das puérperas sobre o parto normal e cesárea. Rev. enferm. UFPE on line, Recife, v.10, n. 8, p. 2801-2808, 2016.

RISCADO, L. C.; JANNOTTI C. B.; BARBOSA, R. H. S. A decisão pela via de parto no Brasil: temas e tendências na produção de saúde pública. Texto \& contexto enferm., Florianópolis, v. 25, n.1, p.1-10, 2016.

REIS, S. L. S. dos et al. Parto normal x Parto cesáreo: análise epidemiológica em duas maternidades no Sul do Brasil. Rev. AMRIGS, Porto Alegre, v. 53, n. 1, p.7-10, 2009.

RODRIGUES, A. V.; SIQUEIRA, A. A. F. de. Sobre as dores e temores do parto: dimensões de uma escuta. Rev. Bras. Saúde Mater. Infant., Recife, v. 8, n. 2 , p. 179-186, 2008.

RUIZ-OLABUÉNAGA, J. I. Metodologia de la investigación cualitativa. 5. ed. Bilbao, España: Universidad de Deusto, 2012.

SANTOS, D. da S.; NUNES, I. M. Doulas na assistência ao parto: concepção de profissionais de Enfermagem. Esc. Anna Nery, Rio de Janeiro, v. 13, n. 3, p.582-589, 2009.

SANTOS, dos L. M. et al. Relacionamento entre profissionais de saúde e parturientes: um estudo com desenhos. Rev. enferm. UFSM, Santa Maria, v.1, n.2, p. 225-237, 2011.

SANTOS, R. A. A.; MELO, M. C. P.; LEAL, R. J. M. Experiência do tipo de parto: relato de puérperas através da análise de discurso. Rev. Ciênc Méd. Biol., Salvador, v. 14, n.1, p.74-81, 2015.

SANTOS, I. S.; OKAZAKI, E. de L. F. J. Assistência de enfermagem ao parto humanizado. Rev. Enferm. UNISA, [s.I], v.13, n.1, p. 64-68, 2012.

SILVA, da D. O. et al. O desejo da mulher em relação a via de parto: uma revisão de literatura. Semina cienc. biol. saúde, Londrina, v.3, n.1, p.103-114, 2015.

SILVA, S. P. C. e S.; PRATES, R. de C. G.; CAMPELO, B. Q. A. Parto Normal ou Cesariana? Fatores que influenciam na escolha da gestante. Rev. enferm. UFSM, Santa Maria, v. 4, n.1, p.1-9, 2014.

SOUZA, S. dos S.; FURTADO, M. D.; NISHIDA, F. S. Parto normal ou cesáreo? Fatores que influenciam na decisão de gestantes pela via de parto. Rev. epidemiol. controle infecç., Santa Cruz do Sul, v. 6, n. 4, p.163-168, 2016.

TOSTES, N. A.; SEIDEL, E. M. F. Expectativas de gestantes sobre o parto e suas percepções acerca da preparação para o parto. Temas Psicol., Ribeirão Preto, v. 24, n. 2, p. 681-693, 2016.

VELHO, M. B.; SANTOS, E. K. A. dos.; COLLAÇO, V. S. Parto normal e cesárea: representações sociais de mulheres que os vivenciaram. Rev. bras. enferm., Brasília, v. 67, n.2, p. 2829, 2014.

WEIDLE, W. G. et al. Escolha da via de parto pela mulher: autonomia ou indução? Cad. saúde coletiva, Goiânia, v. 22, n.1, p. 46-53, 2014.

ZANARDO, G. L. P.; CELDERÓN, M.; HABIGZANG, L. F. Violência obstétrica no Brasil: uma revisão narrativa. Psicol. soc., São Paulo, v. 29, 2017.

Submetido em: 16/05/2018

Aceito em: 19/10/2018 